\title{
A study on the inhibition of mild steel corrosion in hydrochloric acid environment by 4-methyl-2-(pyridin-3-yl)thiazole-5- carbohydrazide
}

\section{T.A.Salman, ${ }^{1}$ A.A. Al-Amiery, ${ }^{2}{ }^{2}$ L.M. Shaker, ${ }^{2}$ A.A.H. Kadhum $^{3}$ and M.S. Takriff ${ }^{3}$}

\author{
${ }^{1}$ Chemistry Department, College of Science, Al-Nahrain University, Baghdad, Iraq \\ ${ }^{2}$ Energy and Renewable Energies Technology Center, University of Technology, Baghdad \\ 10001, Iraq \\ ${ }^{3}$ Department of Chemical and Process Engineering, University Kebangsaan Malaysia \\ (UKM), Bangi, Selangor 43000, Malaysia \\ *E-Mail: dr.ahmed1975@gmail.com
}

\begin{abstract}
A new nicotinonitrile derivative, namely 4-methyl-2-(pyridin-3-yl)thiazole-5-carbohydrazide (MPTC), was synthesized and the chemical structure was elucidated using Fourier Transform Infrared Spectroscopy (FT-IR), Nuclear Magnetic Resonance (NMR) and elemental analysis (CHN). The anticorrosion properties of the new synthesized compound MPTC toward mild steel in $1 \mathrm{M} \mathrm{HCl}$ solutions have been investigated using weight loss and scanning electron microscopy (SEM) techniques. The inhibitor concentrations were $0.1 \mathrm{mM}$ to $0.5 \mathrm{mM}$ and the temperatures ranged within 303 to $333 \mathrm{~K}$. The inhibition efficiency increased with an increase in the inhibitor concentration and reached $95.1 \%$ at the concentration of $0.5 \mathrm{M}$ and $303 \mathrm{~K}$. Inhibition efficiency increased in parallel with increasing inhibitor concentration and decreased with rising temperature. The inhibition process was attributed to physical adsorption. The results obtained from the usage techniques show that new synthesized inhibitor could serve as an efficient corrosion inhibitor of mild steel in strong acid environment. The investigated inhibitor obeys the Langmuir adsorption isotherm equation. It was found that the corrosion inhibition performance depends on the concentration of the studied inhibitor and the solution temperature. Quantum chemical calculations have been done to correlate the electronic characteristics of the synthesized inhibitor with the corrosive inhibitive impact. Experimental and theoretical results are in good agreement.
\end{abstract}

Keywords: 4-hydroxycoumarin, ${ }^{13}$ C NMR, corrosion inhibitor, weight loss.

Received: August 4, 2019. Published: November 25, 2019

doi: $\underline{10.17675 / 2305-6894-2019-8-4-14}$

\section{Introduction}

Corrosion consequences are considered as a major problem of international importance. Corrosion takes charge of several accidents and plant shut-downs, cost designs and 
maintenance. In addition, valuable resources are wasted due to the industrial environment harmful nature on metallic surfaces of structures and equipment such in steel acid pickling process, chemical processing factories, oil well acidification, etc. [1,2]. Protecting mild steel from corrosion is the challenging topic of many scientific research due to its various industrial applications. Till date, several effective techniques have been applied involving cathodic protection [3], organic coating method [4-6], inhibitors [7-11], and employing of corrosion resistant alloys. Metallic Corrosion inhibitors presented in previous studies are heteroatoms contain organic compounds. These inhibitors can be utilized during metal or alloy pickling process and can be used in oil acidization [12-15]. Studies have also confirmed that the effectiveness of the inhibitors relies on heteroatoms existence, $\pi$ electrons, non-bonding electrons and the aromatic rings [16]. These inhibitors adsorption is conditioned by adsorption sites, metal, testing medium and temperature of solutions etc. [17]. Following up of several previous researches for efficient mild steel corrosion inhibitors in acidic solutions [18-39]. This study reports the impact of a synthesized inhibitor derived from nicotinonitrile, namely 4-methyl-2-(pyridin-3-yl)thiazole-5carbohydrazide (MPTC) on the corrosion of mild steel in $\mathrm{HCl}$ environment.

\section{Experimental Section}

\subsection{Chemistry}

The chemical compounds and solvents which utilized for synthesis were from Sigma/Aldrich. The Fourier-transform infrared spectroscopy (FTIR) spectra were recorded on a Nicolet 6700 FT-IR spectrophotometer, and the energy is reported in $\mathrm{cm}^{-1}$. Nuclear magnetic resonance (NMR) spectra were performed utilizing an AVANCE III $600 \mathrm{MHz}$ spectrometer, using Dimethyl sulfoxide as an internal standard and sigma values are reported in ppm.

\subsubsection{Synthesis of ethyl 4-methyl-2-(pyridin-3-yl)thiazole-5-carboxylate}

A mixture of equimolar amounts of the pyridine-3-carbothioamide (2.763 gm, $20 \mathrm{mmol})$ and ethyl 2-chloroacetoacetate $(3.280 \mathrm{gm}, 20 \mathrm{mmol})$ was stirred and heated at reflux at $65-70^{\circ} \mathrm{C}$ for ten hours. The mixture was poured into ice cold water. The products were isolated and recrystallized from ethanol. Yield $73 \%$; m.p. $164^{\circ} \mathrm{C}$. FT-IR $\left(\mathrm{cm}^{-1}\right): 3069.8$ (C-H aromatic), 2937.3 and $2966.8\left(\mathrm{C}-\mathrm{H}\right.$ aliphatic), $1713.7(\mathrm{C}=\mathrm{O})$ and $1582.3(\mathrm{C}=\mathrm{N}) .{ }^{1} \mathrm{H}$ $\operatorname{NMR}\left(\mathrm{CDCl}_{3}, \mathrm{ppm}\right): 1.38\left(\mathrm{t}, 3 \mathrm{H},-\mathrm{CH}_{3}\right), 2.71\left(\mathrm{~s}, 3 \mathrm{H},-\mathrm{CH}_{3}\right), 4.91\left(\mathrm{q}, 2 \mathrm{H}, \mathrm{CH}_{2}\right)$ and $7.22 \mathrm{t}$, $7.91 \mathrm{~d}, 8.01 \mathrm{~d}, 8.24 \mathrm{~d}$ for aromatic ring. ${ }^{13} \mathrm{C} \mathrm{NMR}\left(\mathrm{CDCl}_{3}, \mathrm{ppm}\right): 15.1\left(-\mathrm{CH}_{3}\right), 17.9\left(-\mathrm{CH}_{3}\right)$, $57.5\left(-\mathrm{CH}_{2}-\right), 124.4,127.0,133,7,136.3$ and 143.2 ( $\mathrm{C}$ in Aromatic ring), $139.8(\mathrm{C}-\mathrm{C})$, $154.3(\mathrm{C}=\mathrm{N}), \quad 161.6(\mathrm{C}=\mathrm{N}), \quad 167.1 \quad(\mathrm{C}=\mathrm{O}) . \quad \mathrm{CHN}$ analysis for $\mathrm{C}_{12} \mathrm{H}_{12} \mathrm{~N}_{2} \mathrm{O}_{2} \mathrm{~S}$, Calculated/Found: C, 58.05/57.98, H, 4.87/4.81 and N, 11.28/11.12. 


\subsubsection{Synthesis of 4-methyl-2-(pyridin-3-yl)thiazole-5-carbohydrazide}

A mixture of equimolar amounts of the of ethyl 4-methyl-2-(pyridin-3-yl)thiazole-5carboxylate $(2.483 \mathrm{gm}, 10 \mathrm{mmol})$ and hydrazine hydrate $(5.0 \mathrm{~mL})$ was stirred and heated at reflux at $90^{\circ} \mathrm{C}$ for ten hours. The products were isolated and recrystallized from ethanol. Yield 81\%; m.p. $150^{\circ} \mathrm{C}$; FT-IR $\left(\mathrm{cm}^{-1}\right)$ : 3337.1, 3355.8 (amino groups), $3006.5(\mathrm{C}-\mathrm{H}$ aromatic), $2907.2\left(\mathrm{C}-\mathrm{H}\right.$ aliphatic), and $1633.4(\mathrm{C}=\mathrm{O}) .{ }^{1} \mathrm{H} \mathrm{NMR}\left(\mathrm{CDCl}_{3}, \mathrm{ppm}\right): 3.98(\mathrm{~d}$, $\left.2 \mathrm{H},-\mathrm{NH}_{2}\right), 8.72(\mathrm{t}, 1 \mathrm{H},-\mathrm{NH}), 2.54\left(\mathrm{~s}, 3 \mathrm{H},-\mathrm{CH}_{3}\right), 4.91\left(\mathrm{q}, 2 \mathrm{H}, \mathrm{CH}_{2}\right)$ and $7.41 \mathrm{~d}, 8.07 \mathrm{~d}$, $8.41 \mathrm{~d}, 8.64 \mathrm{~d}$ for aromatic ring. ${ }^{13} \mathrm{C} \mathrm{NMR}\left(\mathrm{CDCl}_{3}, \mathrm{ppm}\right): 17.2\left(-\mathrm{CH}_{3}\right), 124.8,127.2,133.1$, 138.3 and $143.2(\mathrm{C}$ in Aromatic ring), $154.9(\mathrm{C}=\mathrm{N}), 159.4(\mathrm{C}=\mathrm{N}) . \mathrm{CHN}$ analysis for $\mathrm{C}_{10} \mathrm{H}_{10} \mathrm{~N}_{4} \mathrm{OS}$, Calculated/Found: C, 51.27 /17.98, H, 4.30/4.44 and N, 23.91/23.62.

\subsection{Gravimetric Experiments}

\subsubsection{Mild Steel Specimens}

Coupons of Mild steel (MS) have been supplied from Company of Metal Samples and utilized for this investigation. MS coupons composition (wt \%) were as follows: iron (Fe), 99.21; carbon (C), 0.21; silicon ( $\mathrm{Si}), 0.38$; phosphorous $(\mathrm{P}), 0.09$; sulphur $(\mathrm{S}), 0.05$; manganese $(\mathrm{Mn}), 0.05$; and aluminum $(\mathrm{Al}), 0.01$. In accordance with every immersion time, the coupons were removed and polished mechanically on emery papers (from 600 to 1200), rinsed with multiple deionized water, degreased with acetone, dried in hot air, then reweighed according to the ASTM standard procedure G1-03 [40]. The calculations were conducted in aerated, hydrochloric environment at the concentration of $1.0 \mathrm{M}$ (non-stirred) which have various concentrations of 4-methyl-2-(pyridin-3-yl)thiazole-5-carbohydrazide.

\subsubsection{Weight Loss Technique}

Coupons of MS were utilized with rectangular shape of surface area of $5.0 \mathrm{~cm}^{2}$ and the height of the rectangle was equal to $0.025 \mathrm{~cm}$. The coupons (duplicate) were suspended in $200 \mathrm{~mL}$ of the corrosive $1 \mathrm{M} \mathrm{HCl}$ environment, in the absence and presence of various concentrations $(0.1,0.2,0.3,0.4$ and $0.5 \mathrm{mM})$ of 4-methyl-2-(pyridin-3-yl)thiazole-5carbohydrazide. After immersion for 1, 5, 10, 24, 48 and $72 \mathrm{~h}$, the MS coupons were removed, washed, dried, and weighed accurately. Inhibition efficiencies (IE\%) were calculated through Equation (1):

$$
\operatorname{IE}(\%)=\left[1-\frac{w_{2}}{w_{1}}\right] \times 100
$$

where $w_{1}$ is the weight in the absence of the inhibitor and $w_{2}$ is the weight in the presence of the inhibitor. 
The corrosion rates (CRs) [41] were calculated through utilizing Equation (2) [42]:

$$
C R\left(\frac{\mathrm{mm}}{\mathrm{y}}\right)=\frac{K W}{A T D}
$$

where $K$ is a constant (87.6); $W$ is the weight loss $(\mathrm{mg}) ; A$ is the area $\left(\mathrm{cm}^{2}\right)$; and $D$ is the density $\left(\mathrm{g} / \mathrm{cm}^{3}\right)$.

\section{Results and Discussion}

\subsection{Synthesis}

The sequence for the reaction synthesis of the new inhibitor derived from pyridine is summarized in Scheme 1. Ethyl 4-methyl-2-(pyridin-3-yl)thiazole-5-carboxylate was prepared through the reflux of equimolar amounts of pyridine-3-carbothioamide with ethyl 2-chloroacetoacetate. The FT-IR spectrum of ethyl 4-methyl-2-(pyridin-3-yl)thiazole5-carboxylate demonstrated absorption bands at 3069.8 and $1713.7 \mathrm{~cm}^{-1}$ for $\mathrm{C}-\mathrm{H}$ aromatic and ester carbonyl stretching respectively. The ${ }^{1} \mathrm{H}$ NMR spectrum showed a singlet at $\delta$ $2.71 \mathrm{ppm}$ and quartet due to the three $\mathrm{CH}_{3}$ protons and two $\mathrm{CH}_{2}$ protons. Also a triplet band at $\delta 1.38$ due to the three $\mathrm{CH}_{3}$ protons was observed. The reaction of ethyl 4-methyl2-(pyridin-3-yl)thiazole-5-carboxylate with hydrazine hydrate afforded hydrazide MPTC in a very good yield. The FT-IR spectrum of the MPTC demonstrated absorption bands at 3337.1 and $3355.8 \mathrm{~cm}^{-1}$ (hydrazide $\mathrm{NH}-\mathrm{NH}_{2}$ ) and 1633.4 for carbonyl group. The ${ }^{1} \mathrm{H}$ NMR spectrum exhibited a doublet at $\delta 3.98 \mathrm{ppm}$ due to the two $\mathrm{NH}_{2}$ protons and a triplet due to the single NH proton at $\delta 8.72 \mathrm{ppm}$. Moreover, in the ${ }^{13} \mathrm{C}$ NMR spectrum the signal at $159.4 \mathrm{ppm}$ due to the $\mathrm{C}=\mathrm{N}$ carbon and the signal at $17.2 \mathrm{ppm}$ belonging to the carbon of $\mathrm{CH}_{3}$ group were observed. These signals represent more characteristic evidence for the formation of the synthesized corrosion inhibitor (MPTC).

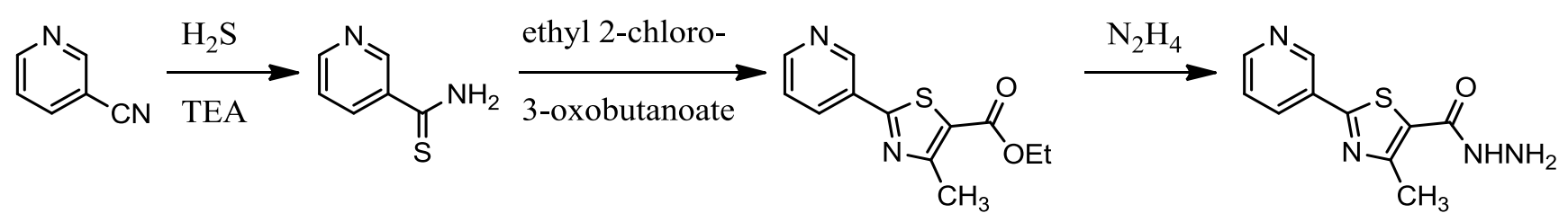

Scheme 1. Synthesis of the corrosion inhibitor MPTC.

\subsection{Weight Loss Method}

\subsubsection{Effect of Concentration and Time}

The weight loss method was applied to calculate corrosion ratios and IE(\%) in an acidic medium over $(1,5,10,2448$ and $72 \mathrm{~h})$ period of time and $303 \mathrm{~K}$ temperature as illustrated in Figures 1 and 2. MPTC reduced the mild steel corrosion in the acid medium significantly. The $\mathrm{IE}(\%)$ value increased when the synthesized inhibitor concentration 
increased and reached its maximum efficiency at $95.1 \%$ of $0.5 \mathrm{mM}$ of MPTC content, which means an increment in MPTC protection efficiency.

The values of inhibition efficiencies calculated from the weight loss technique for MS (mild steel) in the $\mathrm{HCl}$ environment having different concentrations of MPTC at different temperatures such as 303, 313, 323 and $333 \mathrm{~K}$ are demonstrated in Figures 1, 2 and 3. It is shown in the Figures that the MPTC decrease the corrosion of MS in the $\mathrm{HCl}$ environment significantly. The inhibition efficiency increased with a increase in concentration of the synthesized inhibitor and reached maximum inhibition efficiency at $0.5 \mathrm{mM}$ concentration of MPTC. The increase in inhibition efficiency with the increase in concentration is suggestive of the increase in the extent of protection ability of MPTC.

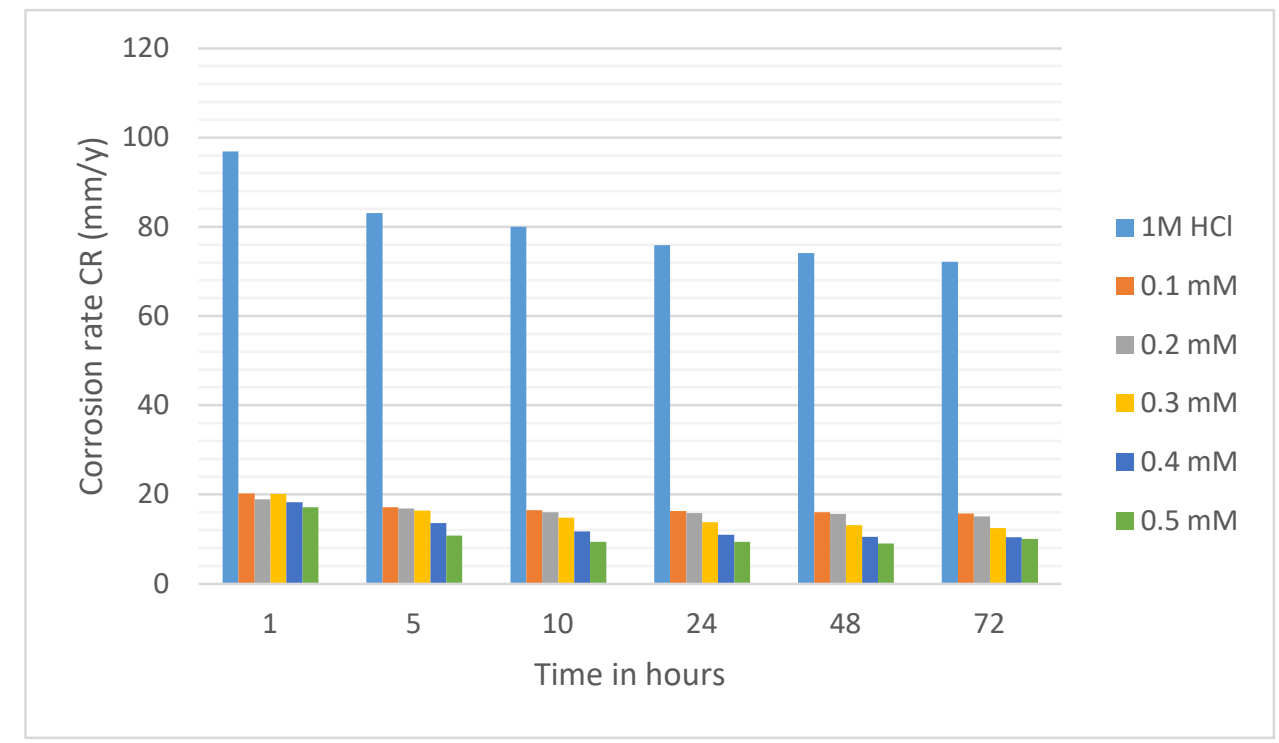

Figure 1. Mild steel corrosion rate as a function of time at $303 \mathrm{~K}$.

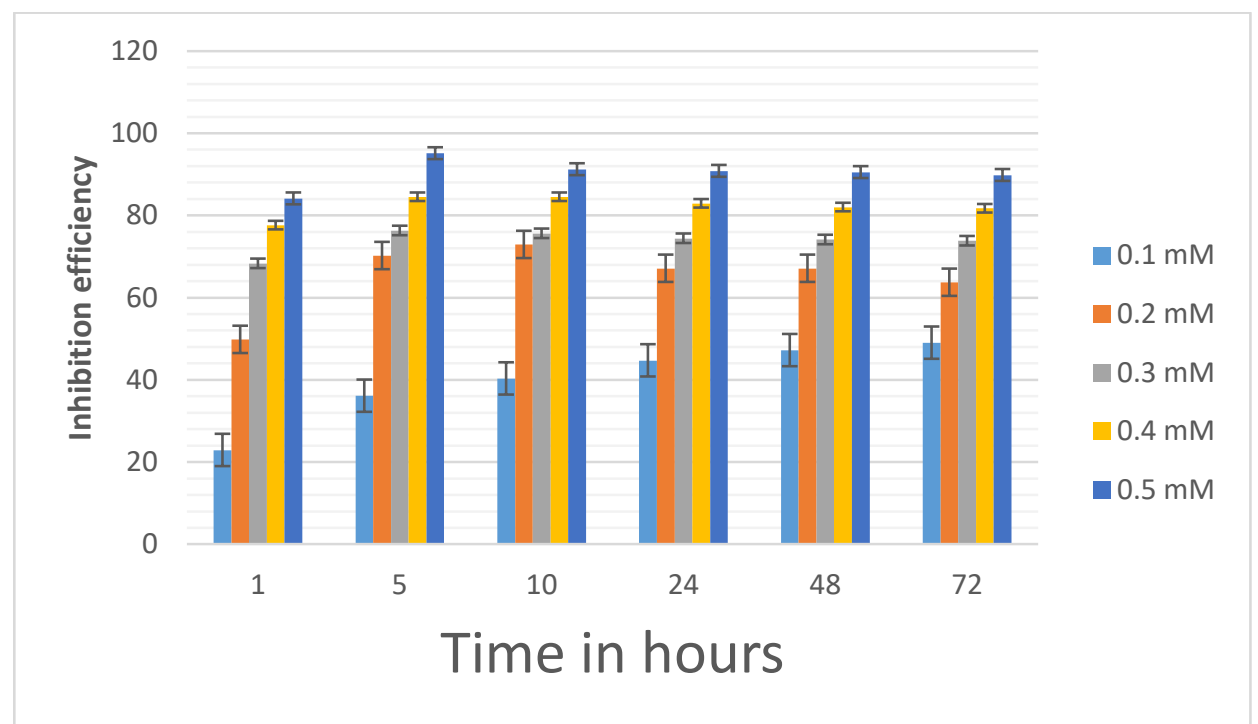

Figure 2. Inhibition efficiency (\%) of mild steel as a function of time at $303 \mathrm{~K}$. 


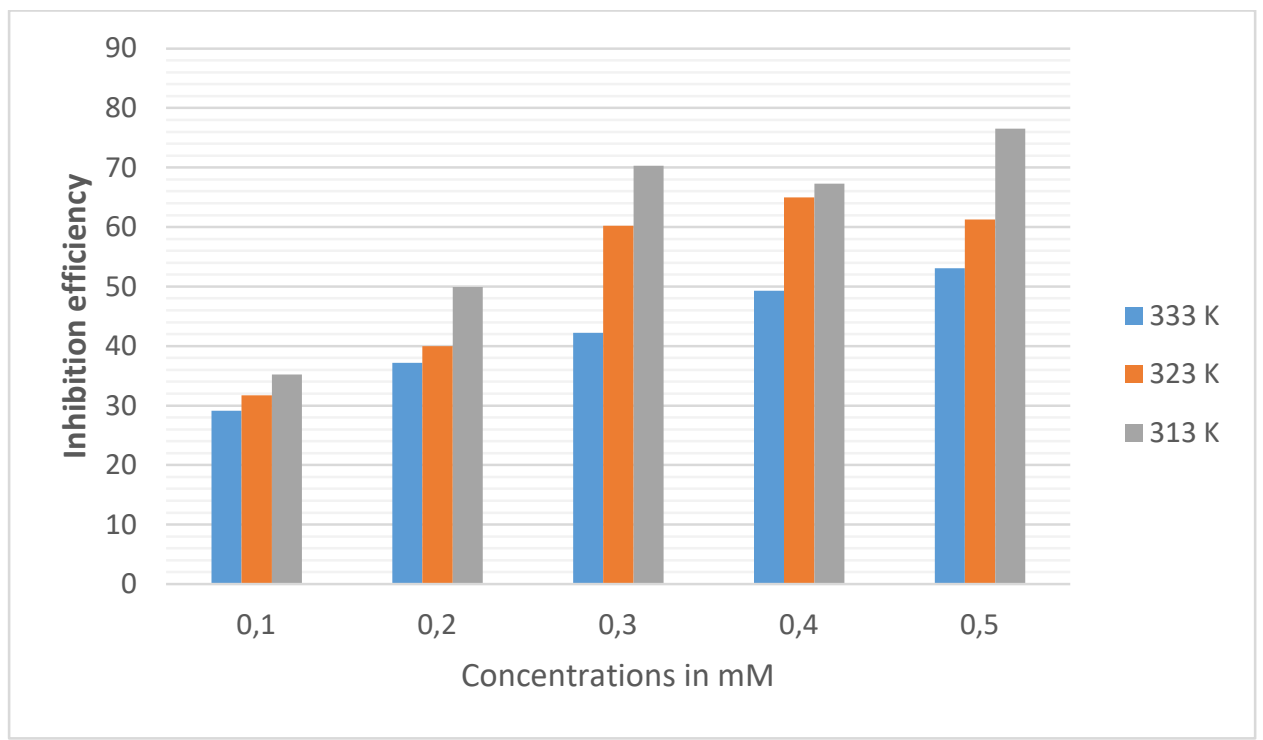

Figure 3. Temperature influence on $\operatorname{IE}(\%)$ of various MPTC concentrations at a given time.

\subsubsection{Temperature effect}

Temperature variation 303, 313, 323 and $333 \mathrm{~K}$ effect involved in Figure (3) to compare MPTC efficiency on mild steel in acidic solutions with different concentrations in the absence and existence of these concentrations, $\operatorname{IE}(\%)$ improved in higher inhibitor concentrations the efficiency has reduced when the temperature increased. In general, the adsorption heat in the process of organic compounds adsorption is negative, which proves the existence of a heat repellent process. So that, the efficiency of the inhibitor decreases as the temperature rises.

\subsection{Scanning Electron Microscopy (SEM) Topography}

The scanning electron microscopy micrograph of surface of mild steel coupons before any treatment is shown in Figure 4.

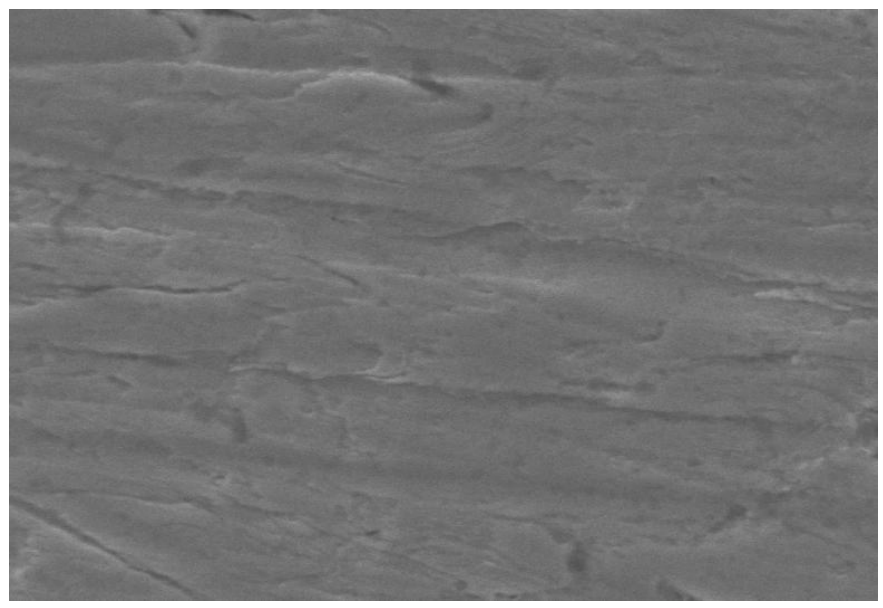

Figure 4. The SEM micrograph of the surface of mild steel coupon before any treatment. 
The SEM micrographs of the surface of mild steel coupon after immersed in $1 \mathrm{M} \mathrm{HCl}$ solution and in inhibited solutions for $5 \mathrm{~h}$ at $303 \mathrm{~K}$ are demonstrated in Figure 5a and 5b. In accordance with every immersion time, the coupons were removed and emery papers were used to polish them mechanically, rinsed with multiple deionized water, degreased with acetone then dried in hot air according to the ASTM standard procedure G1-03 [40]. As shown in Figure 5a, in the absence of MPTC, the surface of mild steel is seriously damaged and fairly rough by the $1 \mathrm{M} \mathrm{HCl}$ environment. The addition of $0.5 \mathrm{mM}$ of MPTC, as in Figure 5b, the surface of mild steel is lightly damaged, which elucidate that the presence of MPTC able to inhibit the corrosion of surface of mild steel effectively in the hydrochloric acid environment $\mathrm{HCl}$ environment. Thus, the adsorption of MPTC molecules will formed the protective layer over the mild steel surface. The observation supported the inhibition potency of MPTC against the corrosion of mild steel in hydrochloric acid environment.

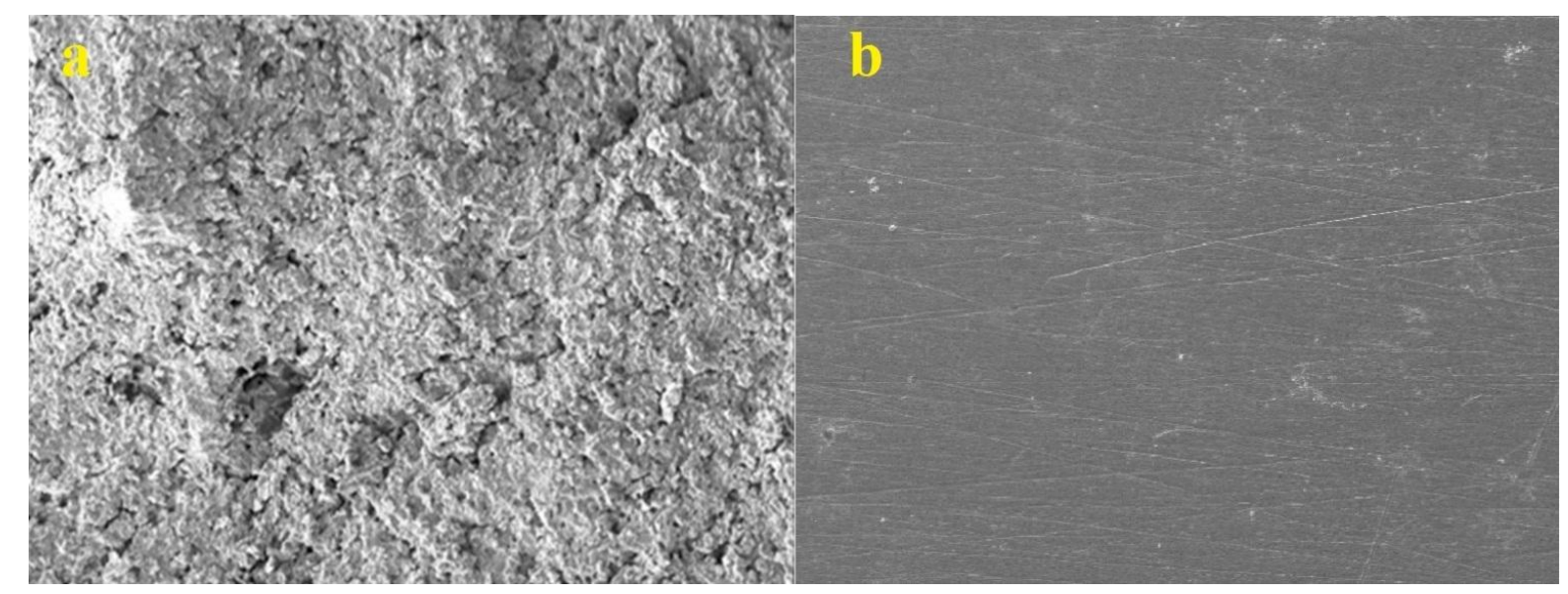

Figure 4. (a) SEM micrograph in the absence of the inhibitor, (b) SEM micrograph in the presence of the inhibitor. Both pictures refer to the mild steel in 1.0 M of HCL acid with corrosion inhibitor $(0.5 \mathrm{mM})$ at $303 \mathrm{~K}$ immersed for $5 \mathrm{~h}$.

\subsection{Adsorption Theory}

To realize the adsorption process, different adsorption isotherms were fitted utilizing the weight loss results. The best fits were obtained when concentration was plotted against concentration/surface coverage $\theta$. Langmuir, Temkin, Frumkin, and Freundlich adsorption isotherms provide an explanation of organic corrosion inhibitors adsorption mechanism on the surface of the metal [43]. Molecular adsorption methodology describes the organic inhibitor corrosion inhibition on mild steel in $\mathrm{HCl}$ acid. The strength of adsorption is controlled by the surface nature and its charge, the electronic state of the surface and the adsorption action of solvents and ions on electrochemical potential at the solution interfaces [44].

Surface coverage $(\theta)$ values of the examined inhibitors with different concentrations have been employed to measure the adsorption process. In this work, we have calculated $\theta$ 
from Equation 3; it is worth mentioning that inhibitor efficiency should be known as indicated in the following formula [45]:

$$
\theta=\frac{I E(\%)}{100}
$$

The plot between $\frac{C_{\text {inh }}}{\theta}$ and $C_{\text {inh }}$ produces a straight line with a slope approximation, indicates that the studied inhibitor obeys Langmuir adsorption isotherm [46]; $\frac{C_{\mathrm{inh}}}{\theta}$ can be calculated mathematically from Equation (4)

$$
\frac{C_{\text {inh }}}{\theta}=\frac{1}{K_{\text {ads }}}+C_{\text {inh }}
$$

where $C_{\text {inh }}$ refers to the inhibitor content and $K_{\text {ads }}$ is a constant value of adsorption process; $K_{\text {ads }}$ is gained from straight line interception and it relates to adsorption standard free energy $\Delta G_{\text {ads }}^{0}$ which was estimated to be $-28.07 \mathrm{~kJ} / \mathrm{mol}$ when calculated from Figure (6) and given in Equation (5):

$$
\Delta G_{\mathrm{ads}}^{0}=-R T \ln \left[55.5 K_{\mathrm{ads}}\right]
$$

where the constant of 55.5 is the water molar concentration in solution in $\mathrm{M}$ units, $R$ is the universal gas constant and $T$ represents the absolute temperature.

The strong interaction between both the surface and inhibitor molecules is proved by $\Delta G_{\text {ads }}^{0}$ negative value; $\Delta G_{\text {ads }}^{0}$ indicates also a "spontaneous" adsorption of the used inhibitor on the surface of steel and a strong interaction between the inhibitor molecules and the mild steel surface. In general, about $-20 \mathrm{~kJ} / \mathrm{mol} \Delta G_{\text {ads }}^{0}$ is attributed to physical adsorption, whereas about $-40 \mathrm{~kJ} / \mathrm{mol} \Delta G_{\text {ads }}^{0}$ or higher gained with electrons transport or by sharing them from inhibitor molecules to the steel surface.

\subsection{Kinetic Parameters of Corrosion}

Arrhenius and the difference of transition state plots were employed to determine the activation energy $\left(E_{a}\right)$ in $\left(\mathrm{J} \cdot \mathrm{mol}^{-1}\right)$ unit and the activation entropy $\left(\Delta \mathrm{S}_{\mathrm{a}}\right)$ with the temperature variations at $(303,313,323$ and $333 \mathrm{~K})$ in presence and absence of the MPTC. The corrosion rate $C_{R}$ is given in Equation (6):

$$
C_{\mathrm{R}}=A e^{-E_{\mathrm{a}} / R T}
$$

where $A$ represents the pre-exponential factor and $R$ is the gas constant $\left(8.314 \mathrm{~J} \cdot \mathrm{mol}^{-1} \cdot \mathrm{K}^{-1}\right)$. By taking the natural log of both sides to solve the equation (common log can be applied): 


$$
\ln C_{\mathrm{R}}=\frac{-E_{\mathrm{a}}}{R T}+\ln A
$$

Figure (7) shows the Arrhenius plot in which $E_{\mathrm{a}}$ values were calculated from $-E_{\mathrm{a}} / R$ slope fraction of the straight line graphed in Figure (7). The obtained data are given in Table 1.

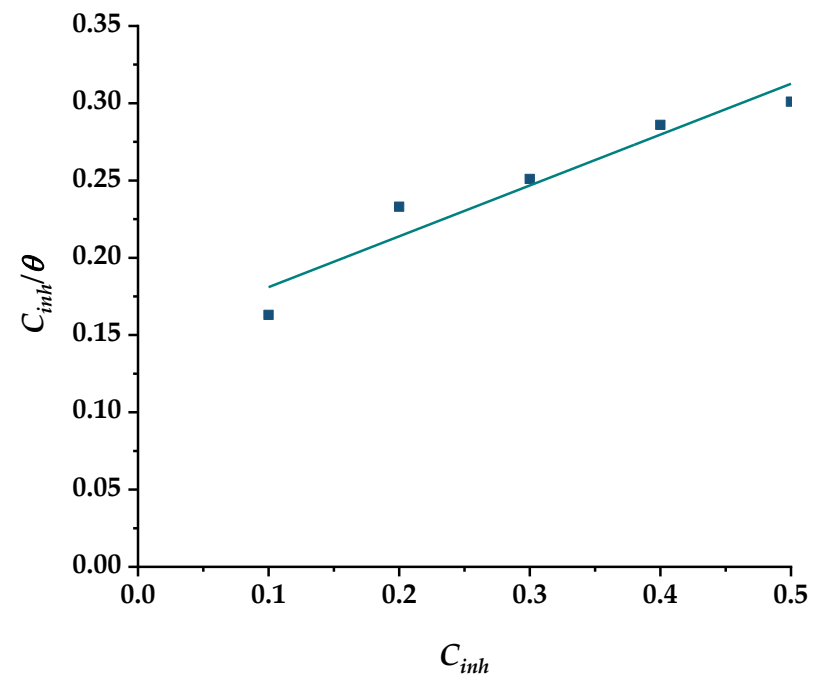

Figure 6. Adsorption isotherm applied for mild steel in $\mathrm{HCl}$ acid (1.0 M). Different inhibitor concentrations were used.

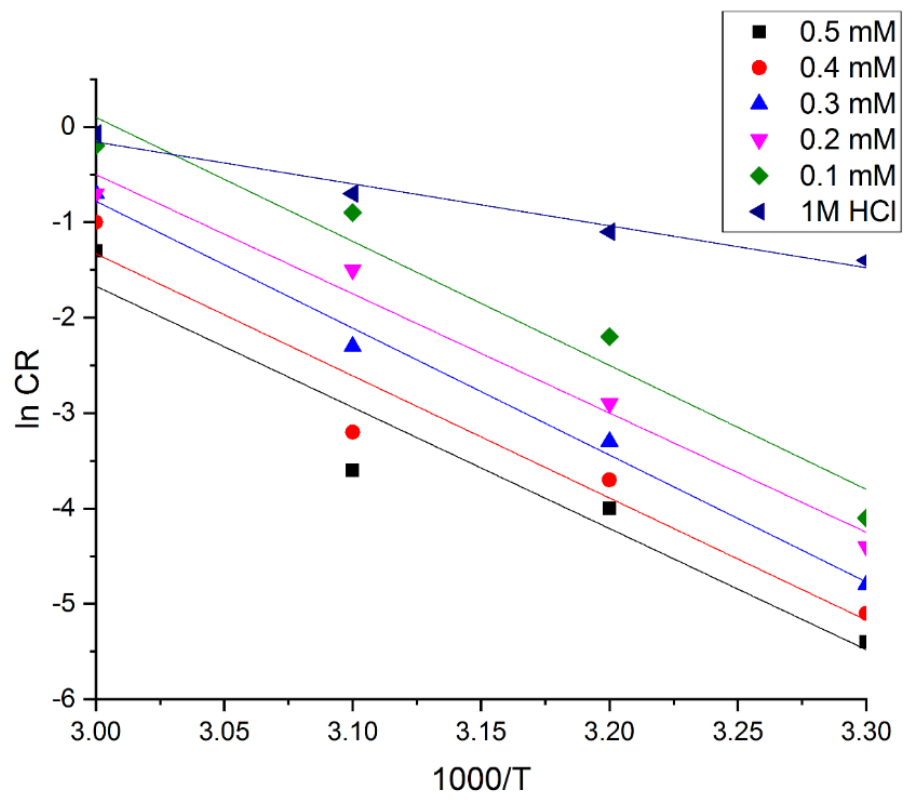

Figure 7. Arrhenius law plot for mild steel surface immersed in $1.0 \mathrm{M} \mathrm{HCl}$. 
Table 1. Corrosion kinetic parameters of mild steel surface in $1.0 \mathrm{HCl}$ acid in the presence and absence of MPTC.

\begin{tabular}{cccc}
\hline Concentration in $(\mathbf{m M})$ & $\boldsymbol{E}_{\mathbf{a}}\left(\mathbf{k J} \cdot \mathbf{m o l}^{\mathbf{- 1}}\right)$ & $\boldsymbol{\Delta H}_{\mathbf{a}}\left(\mathbf{k J} \cdot \mathbf{m o l}^{\mathbf{- 1}}\right)$ & $\boldsymbol{\Delta S}_{\mathbf{a}}\left(\mathbf{J} \cdot \mathbf{m o l}^{-\mathbf{1}} \cdot \mathbf{K}^{\mathbf{- 1}}\right)$ \\
\hline 1 M HCl & 31.7 & - & - \\
0.1 & 36.1 & 73.86 & 17.57 \\
0.2 & 70.2 & 85.47 & 20.17 \\
0.3 & 76.3 & 89.46 & 21.57 \\
0.4 & 84.5 & 90.06 & 21.94 \\
0.5 & 95.1 & 93.88 & 22.27 \\
\hline
\end{tabular}

The other relation namely transition state provided in Equation (8) was applied for the purpose of $\Delta H_{\mathrm{a}}$ and $\Delta S_{\mathrm{a}}$ calculation:

$$
C_{\mathrm{R}}=\frac{R T}{h N} \exp \left(\frac{\Delta S_{\mathrm{a}}}{R}\right) \exp \left(\frac{-\left(\Delta H_{\mathrm{a}}\right)}{R T}\right)
$$

$h$ is Plank's constant $=6.63 \times 10^{-34} \mathrm{~m}^{2} \cdot \mathrm{kg} \cdot \mathrm{s}^{-1}$ and $N$ is Avogadro's number $=6.02 \times 10^{23}$ $\mathrm{mol}^{-1}$. By taking the natural log and rearranging the Equation as follows:

$$
\ln \left[\frac{C_{\mathrm{R}}}{T}\right]=-\left[\frac{\Delta H_{\mathrm{a}}}{R T}\right]+\left\{\ln \left[\frac{R}{h N}\right]+\left[\frac{\Delta S_{\mathrm{a}}}{R}\right]\right\}
$$

As plotted in Figure 8, the straight line slope $=-\Delta H_{\mathrm{a}} / R$ and $\ln (R / N h)+\left(\Delta S_{\mathrm{a}} / R\right)$ is the interception. Both $\Delta H_{\mathrm{a}}$ and $\Delta S_{\mathrm{a}}$ were calculated and inserted in Table (1).

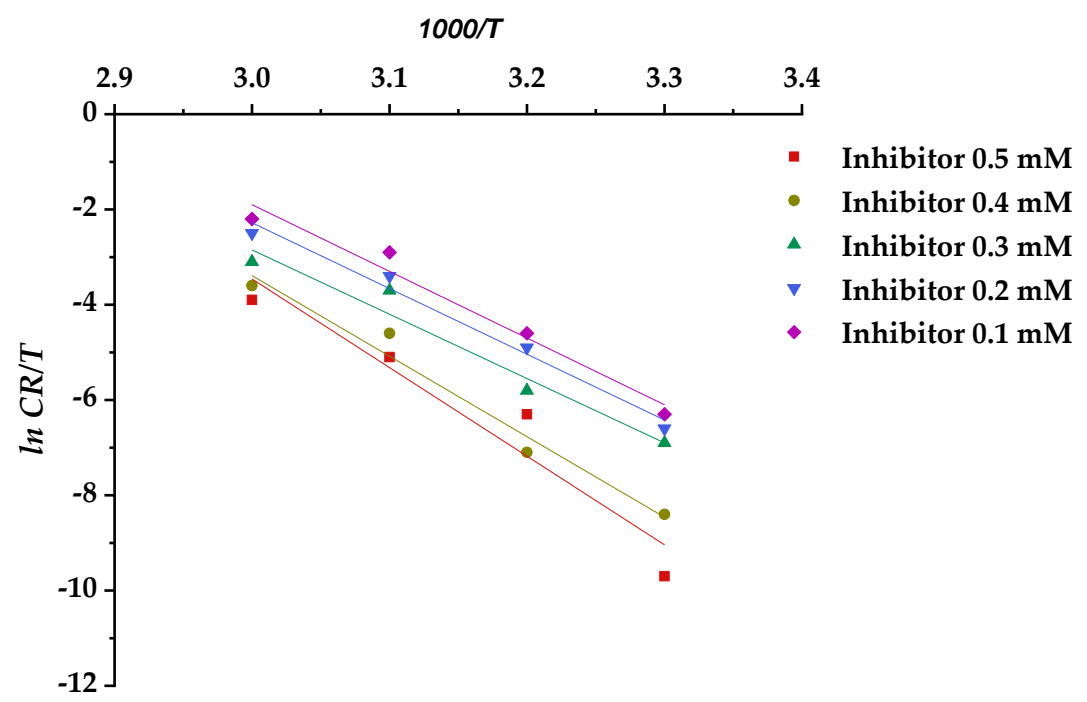

Figure 8. Plot of Transition state for mild steel surface immersed in $\mathrm{HCl}$. 
One can observe from Table (1) that $E_{\mathrm{a}}$ value increased in the presence of the inhibitor. Which means the electrostatic adsorption process is in its primary stage. Also, we have noted that the entire process was limited by the surface reaction because we obtained $E_{\mathrm{a}}>20 \mathrm{~kJ} \cdot \mathrm{mol}^{-1}$ both with and without the inhibitor [47]. These results are supported by previous research [48]; the increment in $E_{\text {a }}$ values can be attributed to reduction of inhibitor adsorption on mild steel surfaces as the temperature gets increased.

While the inhibitors are existing, both $E_{\mathrm{a}}$ and $\Delta H_{\mathrm{a}}$ gained higher values. This proves that the corrosion reaction energy barrier is raised without changing in dissolution mechanism. $\Delta H_{\mathrm{a}}$ positive sign values reflect the dissolution of mild steel endothermic nature in presence and absence of inhibitor for corrosion processes. While $\Delta S_{\text {a }}$ positive signs indicate that the process of adsorption is accompanied by entropy rise. This in turn works as a driving force to facilitate the adsorption of inhibitors on surfaces. As $\Delta H_{\mathrm{a}}$ increases with inhibitor presence, $\Delta S_{\mathrm{a}}$ increases. Mostly this can be explained by disorder increases during the reactant conversion into activated complexes [49].

\subsection{Suggested approaches of activities of new synthesized compound as inhibitor}

According to previous research [50] as well as the results of the current study, a mechanism of corrosion inhibition in an acidic environment has been proposed, and the results are shown in Scheme 2.

The physical adsorption process can be demonstrated as follows, it is supposed that $\mathrm{Cl}^{-}$in the hydrochloric acid unite with the metal surface (positively charged) through Coulomb force first, then, the MPTC molecule is adsorbed between the positively charged molecular and negatively charged MS surface by electrostatic interactions. These adsorbed molecules interacted with $\left[\mathrm{Fe}\left(\mathrm{H}_{2} \mathrm{O}\right) \cdot n \mathrm{Cl}^{-}\right]$to form a monomolecular layer. Cations accept electrons from MS surface to reach stability. The anions consider as donating groups, increased the electron density of $\mathrm{N}, \mathrm{S}$ and $\mathrm{O}$ atoms in the inhibitor molecule. Chemisorption occurs by a retro-donation process. So, the protective layer is deposited on the MS surface to against corrosive environment. Inhibitor role is interpreted chemically by absorbing them on steel surface, where a protective thin layer (blocks the cathodic and/or anodic reactions) is formed or chemical bonds are formed. This is due to the interaction between the metal and the inhibitor molecules. Three adsorption mechanisms that the inhibition process can be continued. The first one, is charged molecules and electrostatically attract of metal. The second mechanism, the interaction occurs between the surface and free electrons. The last mechanism is the metal surface and $\pi$-electron interaction. Our corrosion inhibitor against mild steel corrosion in $1 \mathrm{M}$ of $\mathrm{HCl}$ can be expounded in the account to adsorption sites' number, charge density, size of molecules, interaction of inhibitor with metal surface technique and the ability to form an insoluble complex. From chemical bonds with the metallic surface, $\pi$-electrons involved in both unpaired electrons and double bonds on nitrogen and oxygen atoms are displayed in Scheme 2. 


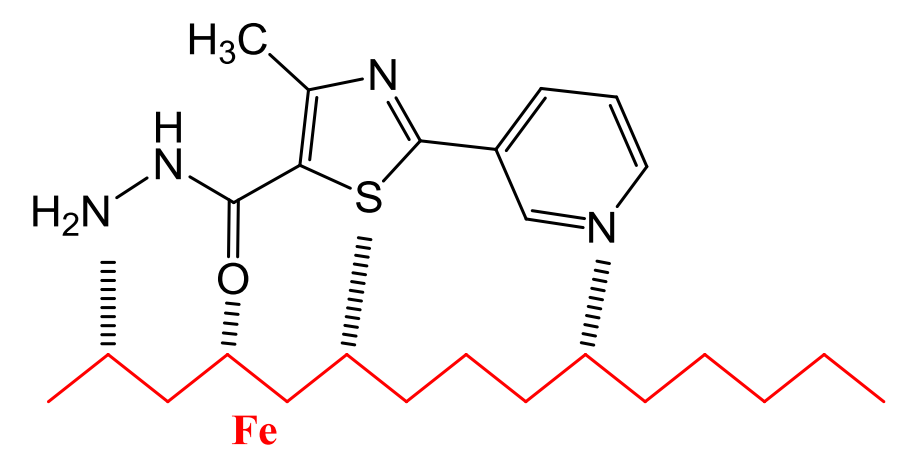

Scheme 2. The proposed action of the synthesized compound mechanism as a corrosion inhibitor.

\subsection{Computational work}

\subsubsection{Geometric isomerism of MPTC}

MPTC may exist as enol or keto isomers with respect to the $\mathrm{C}=\mathrm{O}$ double bond. Performed energy computations were accomplished based on density functional theory (DFT) B3LYP method using the 6-31 G basis set by means of Gaussian 09, revision A.02 method. The resultant MPTC was obtained as a single keto geometrical isomer. This is because of a slight difference in energy acquired; $\Delta E=-39.6432 \mathrm{Kcal} / \mathrm{mol}$ and $-31.9994 \mathrm{Kcal} / \mathrm{mol}$ as it is seen in Figure 9, respectively, between the enol and keto conformers in favor of the former.

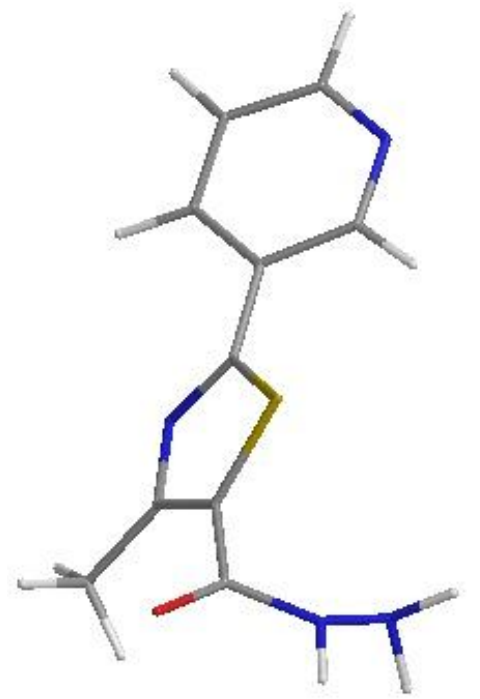

a
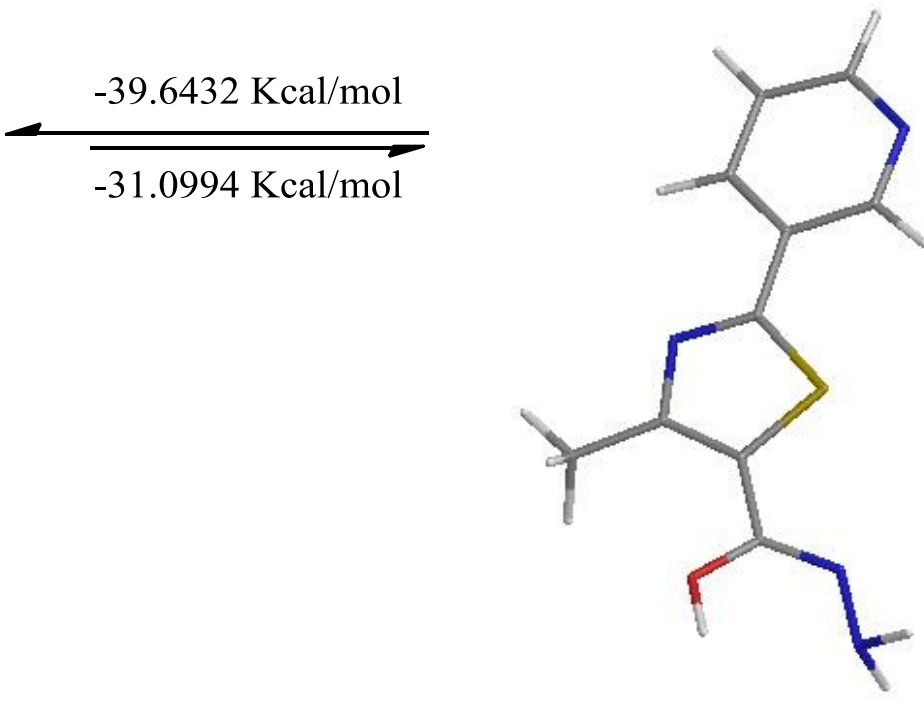

b 


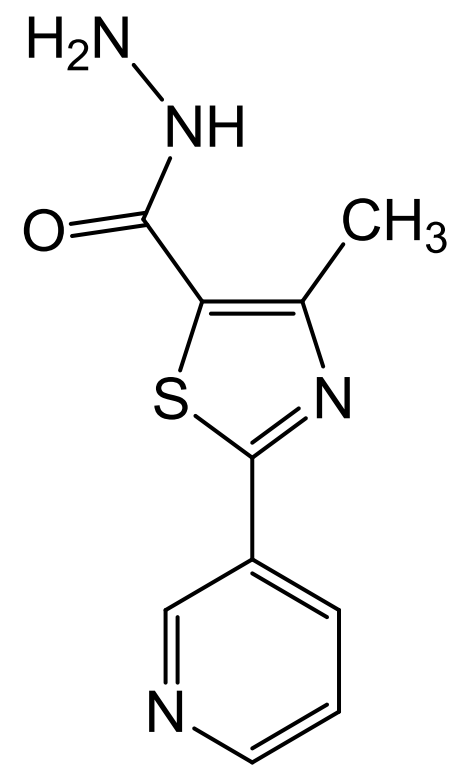

1

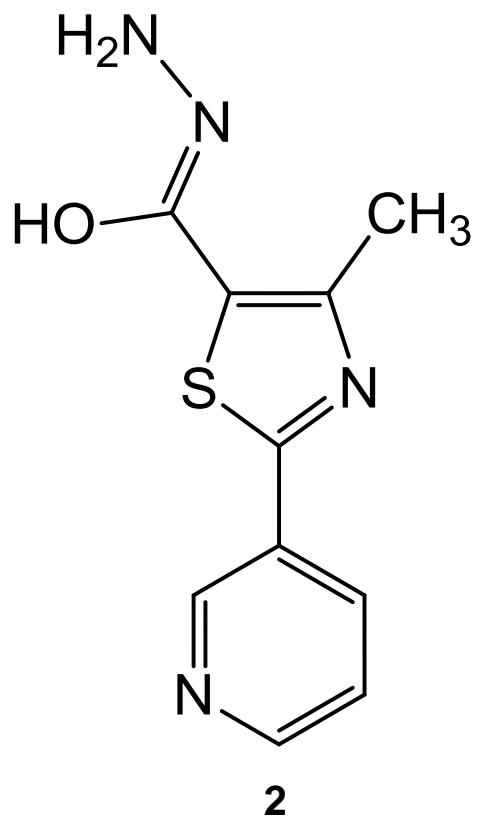

Figure 9. Probable conformational isomers of the $N$-acylhydrazone of MPTC (3-dimensional structures $(\mathrm{a}, \mathrm{b})$ and geometrical isomers $(1,2))$.

\subsubsection{Quantum chemical calculations}

A successful way to characterize both of organic corrosion inhibitor nature structure and the approach of inhibition was achieved by DFT concept. This technique provides us parameters of the electron affinity $(A)$, ionization potential $(I)$, chemical hardness $(\eta)$ and softness (s), electron gravity $(\chi)$ and the last parameter electrophilicity index $(\omega)$ [51]. Quantum parameters have been measured from Equations (10-16) [25]:

$$
\begin{gathered}
\Delta E=E_{\mathrm{HOMO}}-E_{\mathrm{LUMO}} \\
A=-H O M O \\
I=-L U M O \\
\eta=\frac{1-A}{2} \\
s=\frac{1}{\eta} \\
\chi=\frac{1+A}{2} \\
\omega=\frac{\mu}{2 \eta}
\end{gathered}
$$


Sulfur, oxygen and nitrogen atoms found in the molecule as active centers and the easy process of MPTC description and synthesis are two basic factors that MPTC design relies on [52]. Usually, very good organic inhibitors accept free electrons from metals as well as providing free electrons to non-occupied orbital of the same metal [53]. Quantum chemical theoretical calculations were applied for investigation of metal and inhibitor interaction [54]. Fukui, Highest occupied molecular orbital (HOMO), lowest unoccupied molecular orbital (LUMO) and MPTC total electron density are given in Figure (10). Where blue and red iso-surfaces clarified in Figure 10 describe accumulation and losses of electrons, respectively. This acts the difference in electron density. The active centers represented by the molecule HOMO regions at which the electrophiles attack, have contributions from amine, amide and carbonyl. While LUMO orbital accepts the required electrons from the metal by anti-bonding orbitals to create a saturated feedback bonds around thiadiazole ring [55].

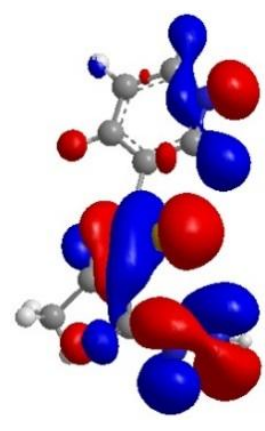

a

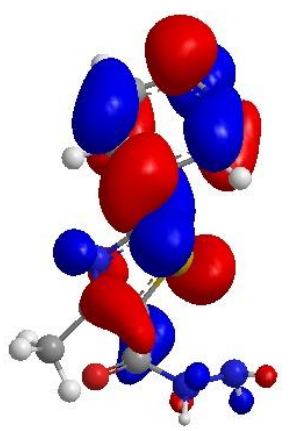

b

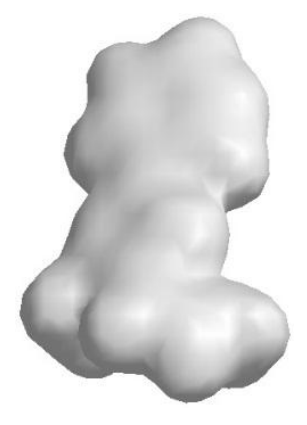

C

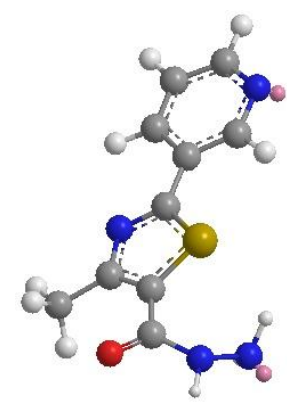

d

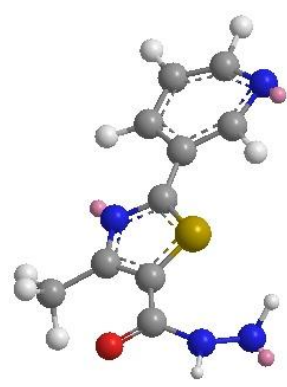

e

Figure 10. Electronic properties of MPTC (a) HOMO orbital; (b) LUMO orbital; (c) total electron density; (d) Fukui $\left(f^{-}\right)$function; (e) Fukui $\left(f^{+}\right)$function.

The orbital energies $E_{\mathrm{HOMO}}, E_{\mathrm{LUMO}}$ and Bipole moment $(\mu)$ are listed in Table 2. High values of $E_{\mathrm{HOMO}}$ imply that the molecule tends to give electrons to low energy molecules or to a suitable acceptor or to an empty orbital. This will facilitate the adsorption currency and increase the value of $\mathrm{IE}(\%)$ as $E_{\mathrm{LUMO}}$ value decreases. Further, $E_{\mathrm{LUMO}}$ depicts the molecule susceptibility toward nucleophilic attack [56]. Low values of energy gap (the difference between $E_{\mathrm{HOMO}}$ and $E_{\mathrm{LUMO}}$ ) denotes that the required energy to remove an electron from the last taken up will be reduced; in accordance to enhanced inhibition efficiencies and effectiveness [57]. Also note that $E_{\mathrm{HOMO}}$ value does not significantly vary for MPTC, which implies that any adsorption strengths would be gained from molecular size. High $\Delta E$ corresponds to nonspecific nature of molecule's interactions with metal surface. More clearly, the reduced $E_{\mathrm{Lumo}}$ value means that the molecule would acquire electrons [58]. 
Table 2. Calculated quantum chemical properties for the most stable conformation of MPTC.

\begin{tabular}{cc}
\hline Function & Values \\
\hline$E_{\mathrm{HOMO}}$ & -0.35565 Hartree \\
$E_{\mathrm{LUMO}}$ & -0.07563 Hartree \\
$E_{\mathrm{HOMO}}-E_{\mathrm{LUMO}}$ & -0.28002 Hartree \\
$f_{\max }^{-}$ & 0.143 \\
$f_{\max }^{+}$ & 0.096 \\
Dipole Moment & -3.4037 \\
$A$ (Electron affinity) & 0.35565 Hartree \\
$I$ (Ionization Potential) & 0.07563 Hartree \\
$\eta$ & 0.14001 Hartree \\
$\mathrm{s}$ & 7.14234 \\
$\chi$ & 0.21564 Hartree \\
$\omega$ & 12.1552 \\
\hline
\end{tabular}

To predict the corrosion inhibition direction, we have to illustrate the measured $\mu$; which is a measure of polarity in a bond and an indicator of electrons distribution within a molecule. Most part of literature concurred that polar compounds adsorption with high $\mu$ values on metallic surfaces ought to promote preferable $\operatorname{IE}(\%)$. The resulted data from this work show that MPTC inhibitor has 3.4037 and 95.1 of $\mu$ and highest IE(\%), respectively. Few researchers believe that the increase in $\operatorname{IE}(\%)$ increases as $\mu$ value increases. However, there is no prior agreement in the literature on the correlation between them [59].

One should anticipate that adsorption orientations are flat-lying because the density of the electrons is saturated around the molecule [57]. The molecule reactivity region was analyzed and estimated by Fukui indices (FI) in term of nucleophilic $\left(f^{+}\right)$and electrophilic $\left(f^{-}\right)$manner. Figure 10d demonstrates the compatibility between $f^{-}$functions and HOMO sites, these sites through which the adsorption process is performed on metal surface. While $f^{+}$in Figure 10e correspond to LUMO sites, at which an interaction between molecule and free electrons on surfaces can occur. High $f^{-}$values relate to $\mathrm{N}, \mathrm{S}$ and $\mathrm{O}$ molecule functions, in contrast to high $f^{+}$values which corresponds to $\mathrm{C}$ atoms of benzene ring functions possess.

In addition to induction and resonance effect, each individual molecule of MPTC possesses hetroatoms, thiazol and pyridine rings. $3^{\text {rd }}$ optimization structure all over MPTC molecule was planar because of the resonance and aromaticity.

To summarize our findings, the electronic MPTC properties were achieved by the DFT-B3LYP employee. As compared with other inhibitor molecules, the MPTC molecules 
have additional electrons to be donated. While LUMO is a measure of molecules affinity, $\Delta E$ gives a description of MPTC and mild steel surface connection; as displayed in Table 2, MPTC has $\Delta E=-0.28002$ Hartree. As illustrated in this paper, the value of $\chi$ supported the methodological findings (efficient inhibitor should have a minimum $\chi$ value).

MPTC molecule adsorption on steel surface is carried out by replacement of water molecules. Furthermore, HOMO/LUMO indicated that HOMO was localized on amino groups and a thiazol ring, but LUMO orbital was switched into a pyridine ring. Finally, MPTC has $\eta=0.14001$ and $S=7.14234$ were assessed in accordance to DFT studies. From these parameters, MPTC considered a perfect inhibitor and has a very good IE(\%).

\subsubsection{Mulliken charge}

MPTC inhibitor Mulliken charge distribution is given in Table 3. More negative values of Mulliken charges of adsorbed center provide the atom the ability to donate an electron for the empty orbitals [60]. It is easy to note that N, S, O and some of $\mathrm{C}$ atoms possess higher charge densities. Highest electron density areas are the locations at which electrophiles can attach [61]. So N, O and some of $\mathrm{C}$ atoms act as active centers; these atoms have the ability to create bonds with the metal surface. In contrary to the other $\mathrm{C}$ atoms that are positively charged atoms, they are often locations where nucleophiles can attach. Therefore, MPTC can also acquire electrons from $\mathrm{Fe}$ atoms as reported in preceding literatures about the excellent corrosion inhibitor characteristics [62].

As stated by frontier orbital theory, HOMO illustrated in Figure 10 is often related to the ability of electron donation of inhibitor molecules. At higher $E_{\mathrm{HOMO}}$ values, molecules tend to give electrons to a metal that contains an empty molecule orbital. As opposed to the ability of molecules to acquire electrons due to low $E_{\text {LUMO }}$ [63], hence it is readily to accept electrons. Eventually, band gap energy which represented by difference relation $E=$ $E_{\mathrm{LUMO}}-E_{\mathrm{HOMO}}$, reflects the amount of $E(\%)$; the lowest the band gap the good the $\operatorname{IE}(\%)$ [64].

\subsubsection{Theoretical comparison studies}

The $E_{\mathrm{HOMO}}$ and $E_{\mathrm{LUMO}}$ are quite significant for characterizing chemical reactivity. The $E_{\mathrm{HOMO}}$ including electrons, illustrates the potency $\left(E_{\mathrm{HOMO}}\right)$ to donate electrons, while, LUMO was an electron acceptor represents the potency $\left(E_{\mathrm{LUMO}}\right)$ to gain an electron. The energy gap between HOMO and LUMO determines the chemical reactivity, kinetic stability, optical polarizability and chemical hardness-chemical softness of a compound [65].

Herein, we calculated the $E_{\mathrm{HOMO}}$ and $E_{\mathrm{LUMO}}$ through utilizing density functional theory (DFT) B3LYP method using the 6-31 G basis set by the means of Gaussian 09, revision A.02 method. $E_{\mathrm{HOMO}}$ higher values refer to an increase to the electron donor which indicate a very good inhibitory efficiency with increasing adsorption of the inhibitor on a surface of mild steel, on the other hand $E_{\mathrm{LUMO}}$ refer to ability of molecule to accept 
electron. The adsorption ability of the inhibitor to the surface of the metal increases with increasing of HOMO and decreasing of LUMO. The $E_{\text {HOMO }}$ and $E_{\text {LUMO }}$ of MPTC, 4methyl-2-(pyridin-3-yl)thiazole-5-carboxamide (MPTC-1) and 4-methyl-2-(pyridin-3yl)thiazole-5-carboxylic acid (MPTC-2) were performed and were shown in Table 4 and Figure 11.

Table 3. Charges (Mulliken charges) for the MPTC.

\begin{tabular}{cccccccc}
\hline Atoms & Charges & Atoms & Charges & Atoms & Charges & Atoms & Charges \\
\hline $\mathrm{C}(1)$ & -0.0559 & $\mathrm{C}(7)$ & -0.1947 & $\mathrm{~N}(13)$ & -0.3437 & $\mathrm{H}(19)$ & 0.1638 \\
$\mathrm{C}(2)$ & -0.1848 & $\mathrm{~N}(8)$ & -0.1160 & $\mathrm{O}(14)$ & -0.3405 & $\mathrm{H}(20)$ & 0.1613 \\
$\mathrm{C}(3)$ & -0.0439 & $\mathrm{C}(9)$ & 0.0168 & $\mathrm{C}(15)$ & -0.1637 & $\mathrm{H}(21)$ & 0.2629 \\
$\mathrm{C}(4)$ & -0.0906 & $\mathrm{C}(10)$ & -0.4823 & $\mathrm{~N}(16)$ & -0.1815 & $\mathrm{H}(22)$ & 0.1066 \\
$\mathrm{C}(5)$ & -0.0557 & $\mathrm{~S}(11)$ & 0.5002 & $\mathrm{H}(17)$ & 0.1655 & $\mathrm{H}(23)$ & 0.1161 \\
$\mathrm{~N}(6)$ & -0.1337 & $\mathrm{C}(12)$ & 0.3639 & $\mathrm{H}(18)$ & 0.1516 & $\mathrm{H}(24)$ & 0.1016 \\
\hline
\end{tabular}

Table 4 presents the calculated values of inhibition efficiency $\%$ for MPTC, MPTC-1 and MPTC-2, which were determined using the following formula:

$$
\begin{gathered}
I_{\text {add. }} \%=\frac{I_{\mathrm{MTCP}}-I_{x-\mathrm{MTCP}}}{I_{\mathrm{MTCP}}} \times 100 \\
I e_{\text {add. }} \%=I_{\text {add. }} \% \times I e_{\mathrm{MTCP}} \% \\
I e_{\text {theor. }} \%=I e_{\mathrm{MTCP}} \%+I e_{\text {add. }} \%
\end{gathered}
$$

where $I_{\text {add. }} \%$ is the percentage ionization potential of the additive for model $(x$ $M T C P), I e_{\text {add. }} \%$ is the inhibition efficiency $\%$ of the additive, and $I e_{\text {theor. }} \%$ is the theoretically calculated percentage inhibition efficiency. 
Table 4. Inhibition efficiencies and some chemical parameters of MPTC, MPTC-1 and MPTC-2 molecules calculated with B3LYP method with 6-31+G(d,p) basis set.

\begin{tabular}{cccc}
\hline Function & MPTC & MPTC-1 & MPTC-2 \\
\hline$E_{\text {HOMO }}$ & -0.3556 Hartree & -0.3547 Hartree & -0.3544 Hartree \\
$E_{\text {LUMO }}$ & -0.0756 Hartree & -0.0824 Hartree & -0.0922 Hartree \\
$E_{\text {HOMO }}-E_{\text {LUMO }}$ & -0.2800 Hartree & -0.2723 Hartree & -0.2622 Hartree \\
Dipole Moment & $-3.4037 \mathrm{D}$ & $-3.3911 \mathrm{D}$ & $-3.3762 \mathrm{D}$ \\
Electron affinity $(A)$ & 0.3556 Hartree & 0.3547 Hartree & 0.3544 Hartree \\
Ionization potential $(I)$ & 0.0756 Hartree & 0.0824 Hartree & 0.0922 Hartree \\
Inhibition efficiency $\%$ & 94.63 & 93.55 & 93.72 \\
\hline
\end{tabular}

The relationships between $E_{\mathrm{HOMO}}$ and $E_{\mathrm{LUMO}}$ of three inhibitors and their IE are demonstrated in Table 4. The inhibition efficiencies have very good correlation with HOMO and LUMO energies. The inhibition efficiencies of corresponding molecules increase with increasing of HOMO energy and decreasing LUMO energy. From above, it can be concluded that $E_{\mathrm{HOMO}}$ and $E_{\mathrm{LUMO}}$ have significant role in determining the inhibition performance of molecules.<smiles>Cc1nc(-c2cccnc2)sc1C(N)=O</smiles>

Chemical structure, MPTC-1

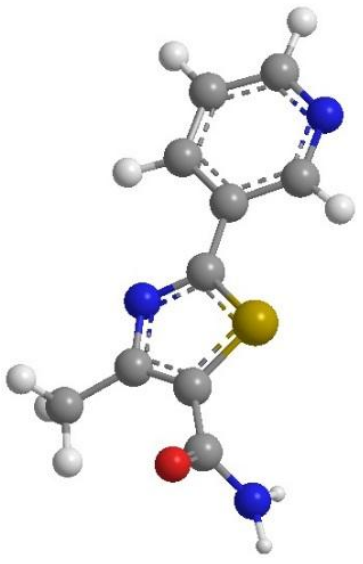

Molecular structure, MPTC-1<smiles>Cc1nc(-c2cccnc2)sc1C(=O)O</smiles>

Chemical structure, MPTC-2

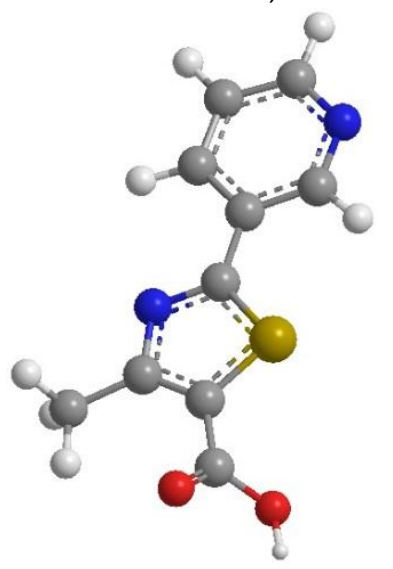

Molecular structure, MPTC-2 


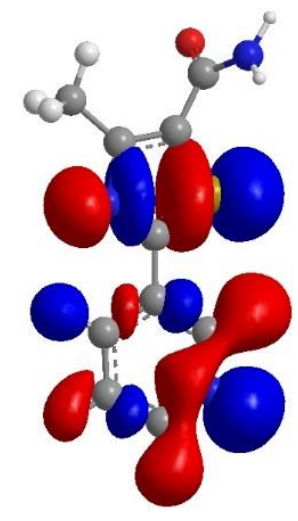

HOMO, MPTC-1

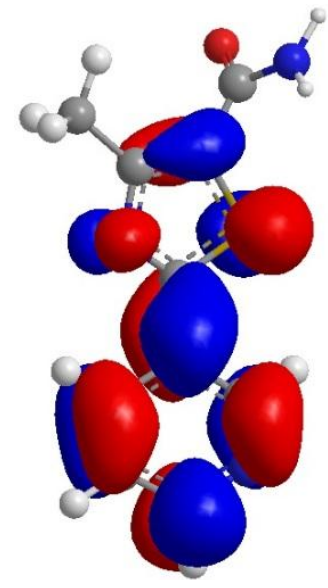

LUMO , MPTC-1

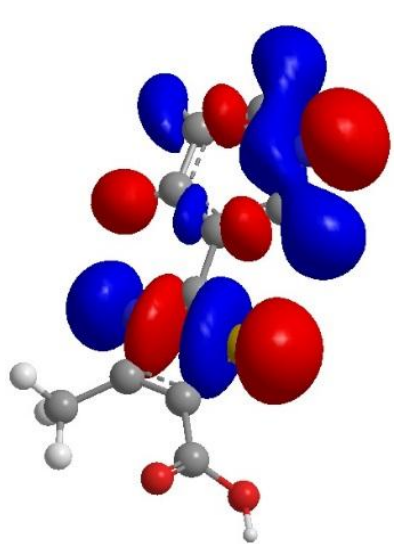

HOMO, MPTC-2

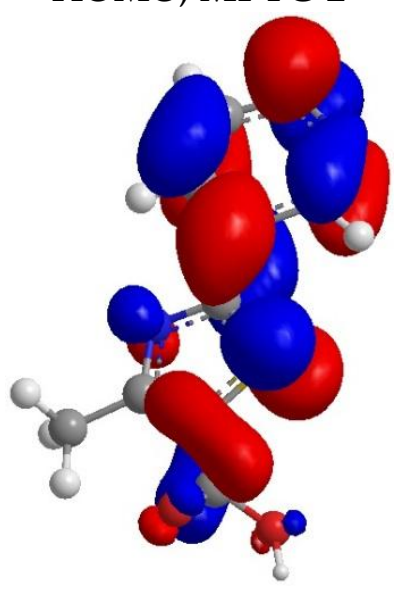

LUMO, MPTC-2

Figure 11. The molecular structures, HOMO and LUMO of MPTC-1 and MPTC-2 by B3LYP with $6-31+\mathrm{G}(\mathrm{d}, \mathrm{p})$ basis set.

The energy gap $(\Delta E)$ between HOMO and LUMO has commonly great significance in realizing the static molecular reactivity. $\Delta E$ with high value indicate high electronic stability resulting in low reactivity, the low value suggest that it will be easy to excitation one electron from HOMO level to LUMO level that intend very good inhibition efficiency. The $\Delta E$ value can be calculated from the difference between HOMO and LOMO energies as demonstrate in Table 4. From Table 4, we can see that there is a relationship between the $\Delta E$ and IE. The IE of corresponding molecules increases of with increasing values of $\Delta E$. The dipole moment $(\mu)$ of a molecule is another significant parameter that gives data on reactivity and polarity. The calculated results display that MPTC has the highest value of dipole moment 3.4037 D with respect to MPTC-1 and MPTC-2 with values of $3.3911 \mathrm{D}$ and $3.3762 \mathrm{D}$, respectively. From here, it can assume that the adsorption of MPTC onto the mils steel surface will be stronger than those of MPTC-1 and MPTC-2, and thus the corresponding inhibition efficiencies will follow the order MPTC $>$ MPTC-1 > MPTC- 2 . From Table 4, the order of electronegativity $(\chi)$ is seen as MPTC-2 > MPTC-1 > MPTC. From Table 4, we can see that the IE has a good negative correlation with $\chi$. The IE of 
corresponding molecules increases of with decreasing values of $\chi$. From Table 4, we can see that the IE has negative correlation with hardness ( $\eta$ ) and positive correlation with softness $(S)$. The IE of corresponding molecules increases of with decreasing values of $\eta$ and with increasing values of $S$.

\section{Conclusions}

Results of the this investigation implied that the new pyridine derivative namely 4-methyl2-(pyridin-3-yl)thiazole-5-carbohydrazide (MPTC) worked as a very good corrosion inhibitor for mild steel in one molar of hydrochloric acid environment in a concentrationdependent technique. IE of MPTC as corrosion inhibitor with highest inhibition efficiency of $95.1 \%$ at the concentration of $0.5 \mathrm{mM}$, and decreases with increasing temperature, that proposed of physisorption. MPTC molecules were adsorbed on surface MS obeying the Langmuir isotherm. MPTC molecules are proved as a very good inhibitor with good inhibitive characteristics due to presence of nitrogen, sulphur and oxygen atoms. SEM measurements confirm the formation of a protective layer by MPTC molecules on the coupon surface. The anti-corrosion study of MPTC molecules, obviously implied its role in the protection of coupon surface in corrosive environment.

\section{Acknowledgments}

This study was supported by the University of Technology, Baghdad, Iraq.

\section{References}

1. X. Li, S. Deng, H. Fu and T. Li, Adsorption and inhibition effect of 6benzylaminopurine on cold rolled steel in $1.0 \mathrm{M} \mathrm{HCl}$, Electrochim. Acta, 2009, 54, no. 16, 4089-4098. doi: 10.1016/j.electacta.2009.02.084

2. I.A. Zaafarany, Corrosion Inhibition of Mild Steel in Hydrochloric Acid Solution using Cationic Surfactant Olyel-amido Derivatives, Int. J. Electrochem. Sci., 2013, 8, 95319542.

3. X. Chen, X.G. Li, C.W. Du and Y.F. Cheng, Effect of cathodic protection on corrosion of pipeline steel under disbonded coating, Corros. Sci., 2009, 51, no. 9, 2242-2245.

4. A. Mahmoodi and M. Ebrahimi, Role of a hybrid dye-clay nano-pigment (DCNP) on corrosion resistance of epoxy coatings, Prog. Org. Coat., 2018, 114, 223-232.

5. A. Yabuki, S. Tanabe and I.W. Fathona, Self-healing polymer coating with the microfibers of superabsorbent polymers provides corrosion inhibition in carbon steel, Surf. Coat. Technol., 2018, 341, 71-77.

6. S.B. Lyon, R. Bingham and D.J. Mills., Advances in corrosion protection by organic coatings: What we know and what we would like to know, Prog. Org. Coat., 2017, 102, $2-7$. 
7. H.H. Zhang, Y. Chen and Z. Zhang, Comparative studies of two benzaldehyde thiosemicarbazone derivatives as corrosion inhibitors for mild steel in $1.0 \mathrm{M} \mathrm{HCl}$, Results Phys., 2018, 11, 554-563.

8. T.A. Salman, K.F. Al-azawi, I. Mahdi, S.B. Al-baghdadi, A.A. Al-amiery, T.S. Gaaz and A.H. Kadhum, Experimental studies on inhibition of mild steel corrosion by novel synthesized inhibitor complemented with quantum chemical calculations, Results Phys., 2018, 10, 291-296.

9. Y. Chen, Y.Y. Jiang, H. Chen, Z. Zhang, J.Q. Zhang and C.N. Cao, Corrosion Inhibition of Mild Steel in Acidic Medium by Linseed Oil-Based Imidazoline, J. Am. Oil Chem. Soc., 2013, 90, 9, 1387-1395.

10. N.A. Odewunmi, S.A. Umoren, Z.M. Gasem, S.A. Ganiyu and Q. Muhammad, 1Citrulline: An active corrosion inhibitor component of watermelon rind extract for mild steel in $\mathrm{HCl}$ medium, J. Taiwan Inst. Chem. Eng., 2015, 51, 177-185.

11. A. Zeino, I. Abdulazeez, M. Khaled, M.W. Jawich and I.B. Obot, Mechanistic study of polyaspartic acid (PASP) as eco-friendly corrosion inhibitor on mild steel in $3 \% \mathrm{NaCl}$ aerated solution, J. Mol. Liq, 2018, 250, 50-62.

12. S. Hejazi, Sh. Mohajernia, M.H. Moayed, A. Davoodi, M. Rahimizadeh, M. Momeni, A. Eslami, A. Shiri and A. Kosari, Electrochemical and quantum chemical study of Thiazolo-pyrimidine derivatives as corrosion inhibitors on mild steel in $1 \mathrm{M} \mathrm{H} 2 \mathrm{SO} 4, J$. Ind. Eng. Chem., 2015, 25, 112-121.

13. J. Haque, C. Verma, V. Srivastava, M.A. Quraishi and E.E. Ebenso, Experimental and quantum chemical studies of functionalized tetrahydropyridines as corrosion inhibitors for mild steel in $1 \mathrm{M}$ hydrochloric acid, Res. Phys., 2018, 9, 1481-1493.

14. A.A. Farag and T.A. Ali, The enhancing of 2-pyrazinecarboxamide inhibition effect on the acid corrosion of carbon steel in presence of iodide ions, J. Ind. Eng. Chem., 2015, 21, 627-634.

15. C. Verma, E.E. Ebenso, I. Bahadur, I.B. Obot and M.A. Quraishi, 5-(Phenylthio)-3Hpyrrole-4-carbonitriles as effective corrosion inhibitors for mild steel in $1 \mathrm{M} \mathrm{HCl}$ : Experimental and theoretical investigation, J. Mol. Liq., 2015, 212, 209-218.

16. R. Hasanov, S. Bilge, S. Bilgiç, G. Gece and Z. Kılıç, Experimental and theoretical calculations on corrosion inhibition of steel in $1 \mathrm{M} \mathrm{H} 2 \mathrm{SO} 4$ by crown type polyethers, Corros. Sci., 2010, 52, no. 3, 984-990.

17. B.O. Hasan and S.A. Sadek, The effect of temperature and hydrodynamics on carbon steel corrosion and its inhibition in oxygenated acid-salt solution, J. Ind. Eng. Chem., 2014, 20, no. 1, 297-303. doi: 10.1016/j.jiec.2013.03.034

18. S. Junaedi, A. Kadhum, A. Al-Amiery, A. Mohamad and M. Takriff, Synthesis and characterization of novel corrosion inhibitor derived from oleic acid: 2-Amino-5-Oleyl1,3,4-Thiadiazol (AOT), Int. J. Electrochem. Sci., 2012, 7, no. 4, 3543-3554. 
19. A.A. Al-Amiery, A.A. H. Kadhum, A.B. Mohamad and S. Junaedi, A novel hydrazinecarbothioamide as a potential corrosion inhibitor for mild steel in $\mathrm{HCl}$, Materials (Basel), 2013, 6, no. 4, 1420-1431. doi: 10.3390/ma6041420

20. A.A. Al-Amiery, A. Kadhum, A. Mohamad, A. Musa and C. Li, Electrochemical Study on Newly Synthesized Chlorocurcumin as an Inhibitor for Mild Steel Corrosion in Hydrochloric Acid, Materials (Basel), 2013, 6, no. 12, 5466-5477. doi: 10.3390/ma6125466

21. A.A.H. Kadhum, A.B. Mohamad, L.A. Hammed, A.A. Al-Amiery, N.H. San and A.Y. Musa, Inhibition of Mild Steel Corrosion in Hydrochloric Acid Solution by New Coumarin, Materials (Basel), 2014, 7, no. 6, 4335-4348. doi: 10.3390/ma7064335

22. A.A. Al-Amiery, A.A.H. Kadhum, A. Kadihum, A.B. Mohamad, C.K. How and S. Junaedi, Inhibition of Mild Steel Corrosion in Sulfuric Acid Solution by New Schiff Base, Materials (Basel), 2014, 7, no. 2, 787-804. doi: 10.3390/ma7020787

23. A.A. Al-Amiery, A.A.H. Kadhum, A.H.M. Alobaidy, A.B. Mohamad and P.S. Hoon, Novel Corrosion Inhibitor for Mild Steel in HCl, Materials (Basel), 2014, 7, no. 2, 662-672. doi: $\underline{10.3390 / \mathrm{ma} 7020662}$

24. A.B. Mohamad, A.A.H. Kadhum, A.A. Al-Amiery, L.C. Ying and A.Y. Musa, Synergistic of a coumarin derivative with potassium iodide on the corrosion inhibition of aluminum alloy in 1.0M H2SO4, Met. Mater. Int., 2014, 20, no. 3, 459-467.

25. H.R. Obayes, G.H. Alwan, A.H. Alobaidy, A.A. Al-Amiery, A.A. Kadhum and A.B. Mohamad, Quantum chemical assessment of benzimidazole derivatives as corrosion Inhibitors, Chem. Cent. J., 2014, 8, no. 21, 1-8. doi: 10.1186/1752-153X-8$\underline{21}$

26. A.A. Al-Amiery, Y.K. Al-Majedy, A.A.H. Kadhum and A.B. Mohamad, New Coumarin Derivative as an Eco-Friendly Inhibitor of Corrosion of Mild Steel in Acid Medium, Molecules, 2015, 20, no. 1, 366-383. doi: 10.3390/molecules20010366

27. E. Yousif, Y.F. Win, A.H. Al-Hamadani, A.A. Al-Amiery, A.A.H. Kadhum, and A.B. Mohamad, Furosemide as an environmental-friendly inhibitor of corrosion of zinc metal in acid medium: Experimental and theoretical studies, Int. J. Electrochem. Sci., 2015, 10, no. 2, 1708-1715.

28. A.Y.I. Rubaye, A.A. Abdulwahid, S.B. Al-Baghdadi, A.A. Al-Amiery, A.A.H. Kadhum and A.B. Mohamad, Cheery sticks plant extract as a green corrosion inhibitor complemented with LC-EIS/ MS spectroscopy, Int. J. Electrochem. Sci., 2015, 10, no. $10,8200-8209$.

29. A.H. Alobaidy, A. Kadhum, S.B. Al-Baghdadi, A.A. Al-Amiery, A.A.H. Kadhum, E. Yousif and A. B. Mohamad, Eco-friendly corrosion inhibitor: experimental studies on the corrosion inhibition performance of creatinine for mild steel in $\mathrm{HCl}$ complemented with quantum chemical calculations, Int. J. Electrochem. Sci., 2015, 10, no. 5, 3961-3972. 
30. S.B. Al-Baghdadi, F.T.M. Noori, W.K. Ahmed and A.A. Al-Amiery, Thiadiazole as a Potential Corrosion Inhibitor for Mild Steel in $1 \mathrm{M} \mathrm{HCl}, J$. Adv. Electrochem., 2016, 2, no. 1, 67-69.

31. A. Al-Amiery, F. Kassim, A. Kadhum and A. Mohamad, Synthesis and characterization of a novel eco-friendly corrosion inhibition for mild steel in $1 \mathrm{M}$ hydrochloric acid, Sci. Rep., 2016, 6, 1-13. doi: 10.1038/srep19890

32. A. Kadhim, A.K. Al-Okbi, D.M. Jamil, A. Qussay, A.A. Al-Amiery, T.S. Gaaz, A.A.H. Kadhum, A.B. Mohamad and M.H. Nassir, Experimental and theoretical studies of benzoxazines corrosion inhibitors, Results Phys., 2017, 7, 4013-4019.

33. H.R. Obayes, A.A. Al-Amiery, G.H. Alwan, T.A. Abdullah, A.A.H. Kadhum and A.B. Mohamad, Sulphonamides as corrosion inhibitor: Experimental and DFT studies, J. Mol. Struct., 2017, 1138, 27-34.

34. S.B. Al-Baghdadi, F.G. Hashim, A.Q. Salam, T.K. Abed, T.S. Gaaz, A.A. Al-Amiery, A.A. H. Kadhum, K.S. Reda and W.K. Ahmed, Synthesis and corrosion inhibition application of NATN on mild steel surface in acidic media complemented with DFT studies, Results Phys., 2018, 8, 1178-1184.

35. H.J. Habeeb, H.M. Luaibi, R.M. Dakhil, A.H. Kadhum, A.A. Al-Amiery and T.S. Gaaz, Development of new corrosion inhibitor tested on mild steel supported by electrochemical study, Results Phys, 2018, 8, 1260-1267.

36. K.F. Al-Azawi, I.M. Mohammed, S.B. Al-Baghdadi, T.A. Salman, H.A. Issa, A.A. AlAmiery, T.S. Gaaz and A.A.H. Kadhum, Experimental and quantum chemical simulations on the corrosion inhibition of mild steel by 3-((5-(3,5-dinitrophenyl)-1,3,4thiadiazol-2-yl)imino)indolin-2-one, Results Phys., 2018, 9, 278-283.

37. D.M. Jamil, A.K. Al-Okbi, S.B. Al-Baghdadi, A.A. Al-Amiery, A. Kadhim, T.S. Gaaz, A.A.H. Kadhum and A.B. Mohamad, Experimental and theoretical studies of Schiff bases as corrosion inhibitors, Chem. Cent. J., 2018, 12, no. 7, 1-7.

38. M.H.O. Ahmed, A.A. Al-Amiery, Y.K. Al-Majedy, A.A. H. Kadhum, A.B. Mohamad and T.S. Gaaz, Synthesis and characterization of a novel organic corrosion inhibitor for mild steel in $1 \mathrm{M}$ hydrochloric acid, Results Phys., 2018, 8, 728-733. doi: 10.1016/j.rinp.2017.12.039

39. T.A. Salman, D.S. Zinad, S.H. Jaber, M. Al-Ghezi, A. Mahal, M.S. Takriff and A.A. AlAmiery, Effect of 1,3,4-Thiadiazole Scafold on the Corrosion Inhibition of Mild Steel in Acidic Medium: An Experimental and Computational Study, J. Bio Tribo Corros., $2019, \mathbf{5}, 1-11$.

40. G.R. Form, E.S. Raper and T.C. Downie, The crystal and molecular structure of 3thioamidopyridine, Acta Crystallogr., Sec. Struct. Crystallogr. Cryst. Chem., 1973, 29B, 776-782.

41. Q. Deng, H.-W. Shi, N.-N. Ding, B.-Q. Chen, X.-P. He and G. Liu, Novel triazolyl bisamino acid derivatives readily synthesized via click chemistry as potential corrosion inhibitors for mild steel in $\mathrm{HCl}$, Corros. Sci., 2012, 57, 220-227. 
42. Z. Tao, W. He, S. Wang, S. Zhang and G. Zhou, A study of differential polarization curves and thermodynamic properties for mild steel in acidic solution with nitrophenyltriazole derivative, Corros. Sci., 2012, 60, 205-213.

43. J.I. Gopal, S.K. Shukla, P. Dwivedi, S. Sundaram and R. Prakash, Inhibitive Effect of Argemone mexicana Plant Extract on Acid Corrosion of Mild Steel, Ind. Eng. Chem. Res., 2011, 50, no. 21, 11954-11959.

44. Q.B. Zhang, Y.X. Hua, Corrosion inhibition of mild steel by alkylimidazolium ionic liquids in hydrochloric acid, Electrochem. Acta, 2009, 54, no. 6, 1881-1887.

45. A. Aytaç, Ü. Özmen and M. Kabasakaloğlu, Investigation of some Schiff bases as acidic corrosion of alloy AA3102, Mater. Chem. Phys., 2005, 89, no. 1, 176-181.

46. P. Dohare, M.A. Quraishi, C. Verma, H. Lgaz, R. Salghi and E.E. Ebenso, Ultrasound induced green synthesis of pyrazolo-pyridines as novel corrosion inhibitors useful for industrial pickling process: Experimental and theoretical approach, Res. Phys., 2019, 13, 102344.

47. M.A. Migahed, H.M. Mohamed, A.M. Al-Sabagh, Corrosion inhibition of H-11 type carbon steel in $1 \mathrm{M}$ hydrochloric acid solution by N-propyl amino lauryl amide and its ethoxylated derivatives, Mater. Chem. Phys., 2003, 80, no. 1, 169-175.

48. M. Boudalia, A. Guenbour, A. Bellaouchou, A. Laqhaili, M. Mousaddak, A. Hakiki, B. Hammouti and E.E. Ebenso, Corrosion Inhibition of Organic Oil Extract of Leaves Of Lanvandula Stoekas on Stainless Steel in Concentrated Phosphoric Acid Solution, Int. J. Electrochem. Sci., 2013, 8, no. 5, 7414-7424.

49. A.Y. Musa, A.B. Mohamad, A.A.H. Kadhum, M.S. Takriff and L.T. Tien, Synergistic effect of potassium iodide with phthalazone on the corrosion inhibition of mild steel in $1.0 \mathrm{M} \mathrm{HCl}$, Corros. Sci., 2011, 53, no. 11, 3672-3677.

50. W. Li, Q. He, S. Zhang, C. Pei and B. Hou, Some new triazole derivatives as inhibitors for mild steel in acidic medium, J. Appl. Electrochem., 2008, 38, no. 3, 289-295. doi: 10.1007/s10800-007-9437-7

51. A.A.H. Kadhum, A.A. Al-Amiery, M. Shikara, A.B. Mohamad, Synthesis, structure elucidation and DFT studies of new thiadiazoles, Int. J. Phys. Sci., 2011, 6, no. 29, 6692-6697.

52. F. Kandemirli ans S. Sagdinc, Theoretical study of corrosion inhibition of amides and thiosemicarbazones, Corros. Sci., 49, 2007, no. 5, 2118-2130.

53. A.A. Al-Amiery, A.Y. Musa, A.A.H. Kadhum and A.B. Mohamad, The use of umbelliferone in the synthesis of new heterocyclic compounds, Molecules, 2011, 16, no. 8, 6833-6843. doi: $10.3390 /$ molecules 16086833

54. E.E. Ebenso, D.A. Isabirye and N.O. Eddy, Adsorption and quantum chemical studies on the inhibition potentials of some thiosemicarbazides for the corrosion of mild steel in acidic medium, Int. J. Mol. Sci., 2010, 11, no. 6, 2473-2498. doi: $\underline{10.3390 / \mathrm{ijms} 11062473}$ 
55. H. Ashassi-Sorkhabi, B. Shaabani and D. Seifzadeh, Effect of some pyrimidinic Schiff bases on the corrosion of mild steel in $\mathrm{HCl}$ solution, Electrochem. Acta, 2005, 50, no. 16-17, 3446-3452. doi: $10.1016 /$ j.electacta.2004.12.019

56. K.F. Khaled, S.A. Fadl-Allah and B. Hammouti, Some benzotriazole derivatives as corrosion inhibitors for copper in acidic medium: Experimental and quantum chemical molecular dynamics approach, Mater. Chem. Phys., 2009, 117, no. 1, 148-155.

57. M.J. Bahrami, S.M.A. Hosseini and P. Pilvar, Experimental and theoretical investigation of organic compounds as inhibitors for mild steel corrosion in sulfuric acid medium, Corros. Sci., 2010, 52, no. 9, 2793-2803.

58. J.M. Costa and J.M. Lluch, The use of quantum mechanics calculations for the study of corrosion inhibitors, Corros. Sci., 1984, 24, no. 11, 929-933.

59. A.A. Al-Amiery, Antimicrobial and antioxidant activities of new metal complexes derived from (E)-3-((5-phenyl-1,3,4-oxadiazol-2-ylimino)methyl)naphthalen-2-ol, Med. Chem. Res., 2012, 21, no. 10, 3204-3213. doi: 10.1007/s00044-011-9880-1

60. S. Xia, M. Qiu, L. Yu, F. Liu and H. Zhao, Molecular dynamics and density functional theory study on relationship between structure of imidazoline derivatives and inhibition performance, Corros. Sci., 2008, 50, no. 7, 2021-2029.

61. A.Y. Musa, A.A.H. Kadhum, A.B. Mohamad, A.A.B. Rahoma and H. Mesmari, Electrochemical and quantum chemical calculations on 4,4-dimethyloxazolidine-2thione as inhibitor for mild steel corrosion in hydrochloric acid, J. Mol. Struct., 2010, 969, no. 1, 233-237.

62. I.B. Obot, E.E. Ebenso, I.A. Akpan, Z.M. Gasem and A.S. Afolabi, Thermodynamic and density functional theory investigation of sulphathiazole as green corrosion inhibitor at mild steel/hydrochloric acid interface, Int. J. Electrochem. Sci., 2012, 7, 1978-1996.

63. I.B. Obot and N.O. Obi-Egbedi, Anti-corrosive properties of xanthone on mild steel corrosion in sulphuric acid: Experimental and theoretical investigations, Curr. Appl. Phys., 2011, 11, no. 3, 382-392.

64. I.B. Obot and N.O. Obi-Egbedi, Theoretical study of benzimidazole and its derivatives and their potential activity as corrosion inhibitors, Corros. Sci., 2010, 52, no. 2, 657660.

65. M. Govindarajan and M. Karabacak, FT-IR, FT-Raman and UV spectral investigation; computed frequency estimation analysis and electronic structure calculations on 1nitronaphthalene, Spectrochim. Acta, Part A, 2012, 85, no. 1, 251-260. doi: $\underline{10.1016 / j . s a a .2011 .10 .002}$ 